\title{
Assessment of Inferior Alveolar Nerve Canal Position and Accessory Mental Foramen Using CBCT to Overcome Surgical Complication
}

\author{
Sneha Meshram¹, Deepti Gattani', Akhilesh Shewale1, Bhagyashri Gudadhe1, Raja Dhuldhwaj² \\ ${ }^{1}$ Department of Periodontology, Swargiya Dadasaheb Kalmegh Smruti Dental College and Hospital, Nagpur, India \\ ${ }^{2}$ Department of Periodontology, Aditya Dental College, Beed, India \\ Email: sneha.n.meshram@gmail.com
}

How to cite this paper: Meshram, S., Gattani, D., Shewale, A., Gudadhe, B. and Dhuldhwaj, R. (2017) Assessment of Inferior Alveolar Nerve Canal Position and Accessory Mental Foramen Using CBCT to Overcome Surgical Complication. Open Access Library Journal, 4: e3609.

https://doi.org/10.4236/oalib.1103609

Received: April 15, 2017

Accepted: June 25, 2017

Published: June 28, 2017

Copyright $\odot 2017$ by authors and Open Access Library Inc.

This work is licensed under the Creative Commons Attribution International License (CC BY 4.0).

http://creativecommons.org/licenses/by/4.0/

(c) $\underset{\mathrm{EY}}{ }$ Open Access

\begin{abstract}
Introduction: The knowledge of precise location of various mandibular anatomical landmarks is mandatory to obtain the desired surgical outcome. Damage to the nerve can be caused by perforation of the nerve canal during different surgical procedures. Accessory mental foramen (AMF) is a relevant anatomic structure with widespread importance as its presence may cause failure to achieve adequate level of anesthesia using conventional nerve block technique. Aim: To assess the inferior alveolar nerve canal position and accessory mental foramen using CBCT. Objective: 1) To assess the linear relationship of the alveolar nerve canal (ANC) to buccal and lingual cortex, bone crest to canal on both sides of mandible. 2) To identify the occurrence and location of AMF as a rare anatomical variation on both side of mandible. Materials and methods: A total 178 mandibular CBCT scans were examined for AMF and the linear relationship ANC to buccal and lingual cortex, bone crest to canal in both side of mandible was evaluated in cross-section. Result: Out of the studied population, 13 AMF were detected in 12 subjects (9 Males, 4 Females). Gender wise comparison of the linear measurement of the study population in buccal cortex, lingual cortex, cortical width, total width through centre of inferior alveolar nerve canal (IANC) and diameter of inferior alveolar nerve canal (IANC) shows no statistically significant variance $(P>0.05)$. Conclusion: The presence of anatomical variations is frequently neglected. To get rid of iatrogenic injuries during the surgical procedures, it is important to identify these variations by presurgical imaging examination which permits more accurate planning and contributes more successful treatment.
\end{abstract}

\section{Subject Areas}

Dentistry 


\section{Keywords}

Accessory Mental Foramen, Cone Beam Computed Tomography

\section{Introduction}

The knowledge of the precise location of various anatomical landmarks such as mandibular foramen, mandibular canal and mental foramen and the course of mandibular neurovascular bundle is mandatory to obtain the desired surgical outcome of the procedures which are carried out at different levels of mandible. Understanding of these important anatomical landmarks will facilitate to overcome various surgical complications [1] [2].

The inferior alveolar nerve is the major sensory branch of the posterior trunk of the mandibular nerve. It innervates teeth, gingiva and also supplies to mucosa, skin of lower lip and skin of the chin. It passes anteriorly within the mandibular canal (MC) of the lower jaw [3]. In the mandibular canal it runs downwards and forwards, generally below the apices of the molars till the first and second premolars, where it is divided into the terminal incisive and mental branches [4] [5].

Iatrogenic injuries to inferior alveolar nerve (IAN) are a well documented complication of third molar surgeries, implant placement, osteotomies, or fracture repair. The considerable variation in the course, the shape, curve, and direction of the nerve as well as the terminal segment of IAN complicates the regional anatomy. Hence, it is often difficult to predict the exact position of the nerve, thus impeding a proper preoperative planning [6].

Risk of inadvertent IAN injury is associated with various surgical interventions in the area including sagittal split osteotomies or placement of fixation screws. It has been reported that in harvesting procedures involving the mandibular ramus, IAN damage may cause sensory deficits up to $8.3 \%$. In orthognathic surgeries, this sensory change is reported in up to $65.1 \%$ of the cases and after placement of dental implants has been up to $77.8 \%$ [7].

The mental foramen is located on the anterolateral aspect of the mandible, through which the mental nerve emerges, a somatic afferent sensory branch of the alveolar inferior nerve which presents as a single circular, or elliptical, bilateral radiolucent area in the premolar region [8]. This nerve plays an important role in procedures such as administration of local anesthesia and surgical intervention (Kaufman et al., 2000; Imada et al.). Mizbah et al. in 2010, found presence of anatomical variations of bifid and trifid $\mathrm{MC}$ which had an increased risk of injury to inferior alveolar nerve either during extraction or placement of dental implants [9]. However, when it is double or multiple, and smaller than the mental foramen, the additional foramen is termed accessory mental foramen (AMF) (Figure 1) (Sisman et al., 2012). An AMF foramen is reported to be rare, with prevalence ranging from $1.4 \%$ to $10 \%$ (Balcioglu \& Kocaelli, 2009). The evaluations of AMF are clinically important in endodontic treatments and surgical 


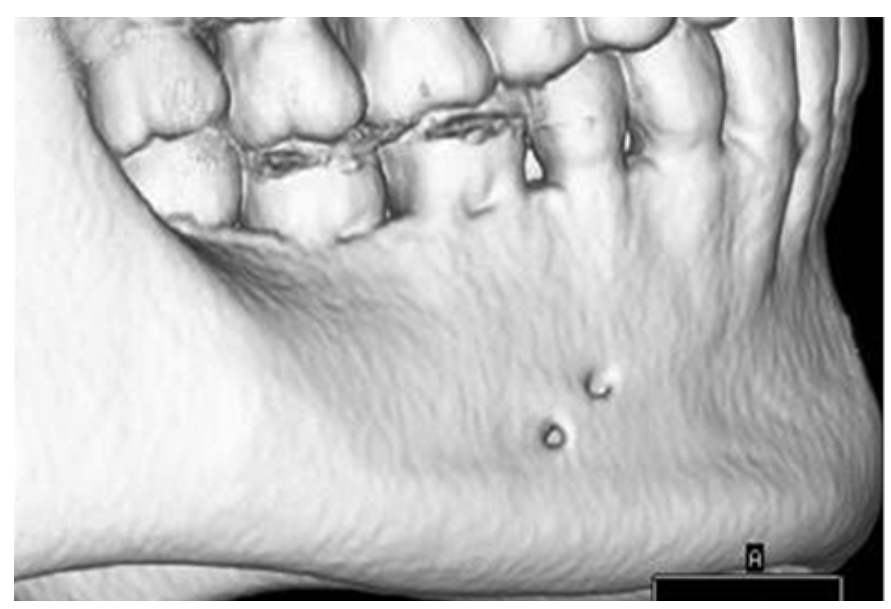

Figure 1. Accessory mental foramen.

procedures such as dental implant insertion, bone grafting and mandibular anterior segmented osteotomy (Sisman et al.). The detection of AMFs may reduce the rates of hemorrhage, postoperative pain and paralysis risk in surgical procedures (Naitoh et al.) [10].

By doing a pre-operative radiographic assessment, the surgeon can provide patients with the necessary information regarding the surgical procedure inform them about the possible risks and prepare them for potential complications [11]. So this study aims to assess the Inferior Alveolar Nerve Canal Position (IANC) and Accessory Mental Foramen (AMF) using CBCT.

\section{Materials and Methods}

Randomly chosen 178 cone beam computed tomography (CBCT) of 104 males and 74 females in the age group of $20-60$ years which was advised by different clinician were considered for this study. The other criteria were as follows: 1) absence of any developmental disturbance or pathology or previous treatment that could influence the IAN or canal or position of tooth including impactions; 2) radiographically completely corticized IAN canal bilaterally; and 3) absence of radiological evidence of skeletal/dental malocclusion that could have altered the position of 1st and 2nd Mandibular Molarand Premolar or IAN. All the CBCTs were taken by the same trained personnel between January 2016 and October 2016 in the same machine, at the same settings. Manufacturer's instructions regarding the positioning and placement were followed. Calibration of the linear measurements had been performed using known dimensions in millimeters. The linear measurements were performed using the software and guides with the same machine. Using the axial, coronal, and sagittal sections, the exact location of the position of IANC (Figure 2) and accessory mental foramen iff present was identified for the study. Linear measurements were made in cross sections. All measurements were measured along the center of the IAN canal unless mentioned specifically. The measurements were the shortest distance between Buccal cortex, Lingual cortex, Cortical width, total width through inferior alveolar nerve, Diameter of inferior alveolar nerve canal, Distance to crest. All the data 


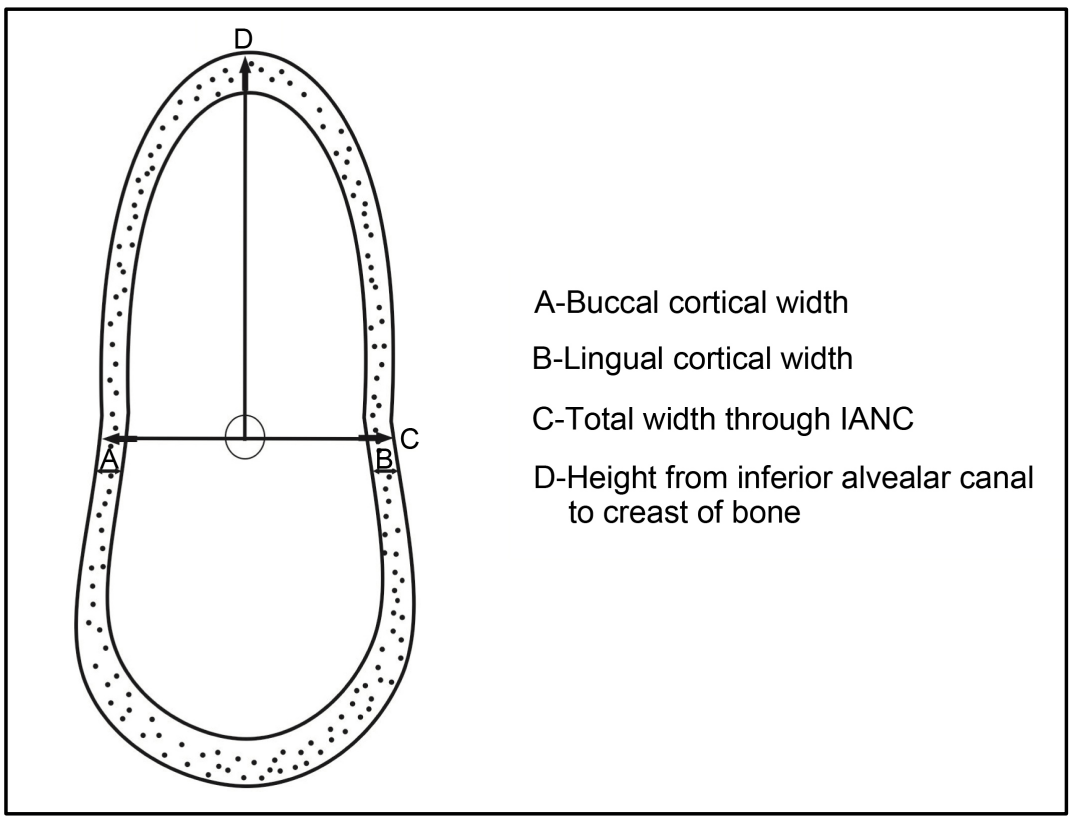

Figure 2. Inferior alveolar canal position.

were entered and analyzed using SPSS, version 20 (SPSS Inc., Chicago, IL). Descriptive statistics of the variables and measurements are presented. $P$ value of $\leq 0.05$ was taken as significant

\section{Result}

A total 356 CBCT scan from 178 subjects (104 males and 74 Females) were used in this study. Out of the studied population, 13 AMF were detected in 12 subjects ( 9 Males, 4 Females). The mean age between male and female of this 13 subjects were mean age of \pm 32.8 (male) and \pm 33 (female) as shown in Table 1 . Gender wise comparison of the linear measurement of the study population in buccal cortex, lingual cortex, cortical width ,total width through centre of inferior alveolar nerve canal (IANC) and diameter of inferior alveolar nerve canal (IANC) shows no statistically significant variance $(P>0.05)$ (Table 2$)$. Mean Distance of Accessory Mental Foramen from Mental Foramen shown in Figure 3.

\section{Discussion}

Two dimensional radiographs do not provide information such as thickness or location of vital structures in a bucccolingual direction. Cross-sectional imaging using conventional spiral, linear, hypocycloidal computed tomogram, and magnetic resonance imaging have been used for cross-sectional imaging. There have been issues with the amount of radiation exposure and the high costs associated with these modalities [6] [12].

The location and the course of the various neurovascular bony canals, such as the bifid mandibular canal, lateral lingual bony canals, and AMFs in the mandible, which are important factors in implant insertion and implant-related bone grafting, have been observed using multislice CT, CBCT images. Naitoh et al. 
Table 1. Details of 13 AMF in 7 subjects detected in present study.

\begin{tabular}{|c|c|c|c|c|c|c|c|c|}
\hline \multirow[b]{2}{*}{ Gender } & \multirow[b]{2}{*}{$\begin{array}{c}\text { Number of } \\
\text { AMF }\end{array}$} & \multirow[b]{2}{*}{$\begin{array}{l}\text { Mean } \\
\text { age }\end{array}$} & \multirow{2}{*}{$\begin{array}{l}\text { Mean } \\
\text { distance } \\
\text { between } \\
\text { MF and } \\
\text { AMF on } \\
\text { right }\end{array}$} & \multirow{2}{*}{$\begin{array}{c}\text { Mean } \\
\text { distance } \\
\text { between } \\
\text { MF and } \\
\text { AMF on } \\
\text { left }\end{array}$} & \multicolumn{4}{|c|}{ Position of AMF to MF } \\
\hline & & & & & Upper & Lower & Anterior & Posterior \\
\hline Male & 9 & 32.8 & $3.5 \pm 1$ & $3.75 \pm 0.7$ & 6 & 3 & 5 & 4 \\
\hline Female & 4 & 33 & $2.4 \pm 1.13$ & $2.35 \pm 1.06$ & 2 & 2 & 3 & 1 \\
\hline
\end{tabular}

Table 2. The linear measurement of the study population in millimeter (right and left side).

\begin{tabular}{ccccccc}
\hline \multirow{2}{*}{$\begin{array}{c}\text { Linear } \\
\text { parameters }\end{array}$} & $\begin{array}{c}\text { Pearson } \\
\text { correlation }\end{array}$ & P value & Total & $\begin{array}{c}\text { Pearson } \\
\text { correlation }\end{array}$ & P value & Total \\
\hline $\begin{array}{c}\text { Buccal cortex } \\
\text { Lingual cortex }\end{array}$ & 0.176 & 0.45 & 105 & 0.389 & 0.81 & 73 \\
$\begin{array}{c}\text { Total width } \\
\text { through center of } \\
\text { IANC }\end{array}$ & 0.031 & 0.89 & 105 & 0.076 & 0.96 & 73 \\
$\begin{array}{c}\text { Diameter of IANC } \\
\begin{array}{c}\text { Distance to the } \\
\text { crest }\end{array}\end{array}$ & 0.454 & 0.69 & 105 & 0.566 & 0.71 & 73 \\
\hline
\end{tabular}

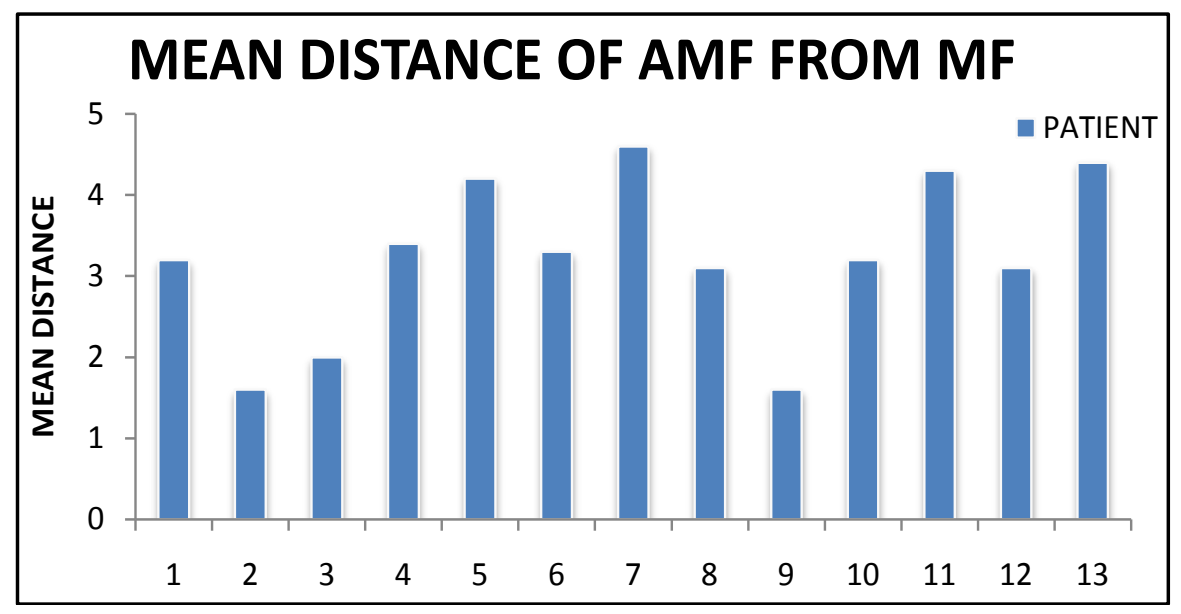

Figure 3. Mean distance of accessory mental foramen from mental foramen.

compared the identification of an accessory mental foramen in panoramic radiographs and in reconstruction images (CBCT). After examining 365 patients, the authors detected 37 accessory mental foramina with the aid of CBCT and only 18 accessory mental foramina on panoramic radiographs [13]. Further Thakur G et al. reported a case in which the accessory mental foramen and its nervous component were discovered accidentally during surgery since the presurgical panoramic radiography had not revealed any variation. Thus, a precise accessory mental foramen analysis is only possible with $\mathrm{CT} / \mathrm{CBCT}$, which provides an im- 
age of better quality and lower distortion than conventional exams do [14].

The foramina located in the surrounding region of the MF have been reported as AMFs although there is no clear definition for AMFs [15]. Prevalence of accessory mental foramen in the present study is $3.56 \%$ GÖREGEN et al. the distance between the MF and the AMF ranged from 1.6 to $4.9 \mathrm{~mm}$, with a mean of $2.54 \mathrm{~mm}$ (SD: $1.1 \mathrm{~mm}$ ). Naitoh et al. reported that the distance ranged from 4.5 to $9.6 \mathrm{~mm}$, with a mean of $6.3 \mathrm{~mm}$ (SD: $1.5 \mathrm{~mm}$ ), and Kalender et al. [16] reported a range of 1.3 to $15.4 \mathrm{~mm}$, with a mean of $5.2 \mathrm{~mm}$ (SD: $4.4 \mathrm{~mm}$ ) [17] [18].

Katakami et al. in a study of 150 patients, observed the presence of 17 accessory mental foramina by CBCT, with $59 \%$ of them being located posterior to the mental foramen. Another study conducted on 157 patients demonstrated the presence of 15 accessory mental foramina, nine of them located posterior to the mental foramen [16].

On the basis of these findings, the present study agreed with the literature since the accessory mental foramina detected here were slightly dislocated in a posterior direction with respect to the mental foramen. The location of the accessory mental foramen would directly affect the planning of rehabilitating treatment since it might interfere with the procedures performed for a dental implant. If the accessory mental foramina would be located inferiorly to the mental foramen for example, the interference caused by their presence will be lower or practically nonexistent since the planning would already be based on the location of the mental foramen .The difference between linear measurements of IANC on right and left sides are not entirely similar in the present study.

\section{Conclusion}

The results showed that all the variables were correlated well (linearly) with the age in both the genders. Significant differences between male and female measurements were detected. Thus with the help of this study it will be helpful for dentist to get rid of iatrogenic injuries, which tend to occur during the surgical procedures. The presence of anatomical variations is frequently neglected. To get rid of iatrogenic injuries during the surgical procedures, it is important to identify these variations by presurgical imaging examination which permits more accurate planning and contributes more successful treatment in assessing the possible post-operative occurrence of labial sensory impairment and thus its prevention.

\section{Clinical Significance}

Thus with the help of this present study it will be beneficial for dental surgeons to assess the bone levels before dental implants placement and other maxillofacial surgeries in the posterior mandibular region.

\section{References}

[1] Ghatak, S. and Yadav, Y. (2012) Comparative Evaluation of Anatomical and Radio- 
graphic Location of Mandibular Foramen, Mandibular Canal and Mental Foramen: A Cadaveric Study of Adult Mandibles of Indian Ethnic Origin. Internal Medicine Journal, 19, 386-389.

[2] Turkyilmaz, I. (2011) Implant Dentistry-A Rapidly Evolving Practice. InTech, Europe, 3-18.

[3] Rake, R.L., Vogl, A.W. and Mitchell, A.W. (2012) Gray's Anatomy for Students. 2nd Edition, Elsevier, Philadelphia, 935.

[4] Assael, L. (2012) Maxillofacial Surgery. InTech, Europe, 71-86.

[5] Ayad, C.E., Elhag, Z.H., Abdalla, E.A., Mohammed, M.E. and Kajoak, S. (2013) Characterization of Inferior Alveolar Canal in Sudanese Populations Using Orthopantomography. International Journal of Medical Imaging, 1, 39-44. https://doi.org/10.11648/j.ijmi.20130103.11

[6] Levine, M.H., Goddard, A.L. and Dodson, T.B. (2007) Inferior Alveolar Nerve Canal Position: A Clinical and Radiographic Study. Journal of Oral and Maxillofacial Surgery, 65, 470-474. https://doi.org/10.1016/j.joms.2006.05.056

[7] Gerlach, N.L., Meijer, G.J., Mall, T.J., Mulder, J., Rangel, F.A., Borstlap, W.A., et al. (2010) Reproducibility of 3 Different Tracing Methods Based on Cone Beam Computed Tomography in Determining the Anatomical Position of the Mandibular Canal. Journal of Oral and Maxillofacial Surgery, 68, 811-817. https://doi.org/10.1016/j.joms.2009.09.059

[8] Neves, F.S., Torres, M.G., Oliveira, C., Campos, P.S. and Crusoe-Rebello, L. (2010) Lingual Accessory Mental Foramen: A Report of an Extremely Rare Anatomical Variation. Journal of Oral Science, 52, 501-503. https://doi.org/10.2334/josnusd.52.501

[9] Dharmar, S. (1997) Locating the Mandibular Canal in Panoramic Radiographs. The International Journal of Oral \& Maxillofacial Implants, 12, 113-117.

[10] Garay, I. and Cantín, M. (2013) Accessory Mental Foramina Assessed by ConeBeam Computed Tomography: Report of Unilateral and Bilateral Detection. International Journal of Morphology, 31, 1104-1108. https://doi.org/10.4067/S0717-95022013000300052

[11] Moshfeghi, M., Ghaznavi, A., Mohseni, M. and Nikneshan, S. (2010) The Ability of Panoramic Radiography in Determining the Relationship of Mandibular Third Molar Roots with the Inferior Alveolar Canal. Dentomaxillofacial Radiology, 39, 79-84.

[12] Peter, I., Alkurt, M.T. and Michioglu, T. (2008) The Use of 3 Different Imaging Methods for the Localization of the Mandibular Canal in Dental Implant Planning. The International Journal of Oral \& Maxillofacial Implants, 23, 463-470.

[13] Naitoh, M., Yoshida, K., Nakahara, K., Gotoh, K. and Ariji, E. (2011) Demonstration of the Accessory Mental Foramen Using Rotational Panoramic Radiography Compared with Cone-Beam Computed Tomography. Clinical Oral Implants Research, 22, 1415-1419.

[14] Thakur, G., Thomas, S., Thayil, S.C. and Nair, P.P. (2011) Accessory Mental Foramen: A Rare Anatomical Finding. BMJ Case Reports, bcr0920103326.

[15] Fuakami, K., Shiozaki, K., Mishima, A., Shimoda, S., Hamada, Y. and Kobayashi, K. (2011) Detection of Buccal Perimandibular Neurovascularisation Associated with Accessory Foramina Using Limited Cone-Beam Computed Tomography and Gross Anatomy. Surgical and Radiologic Anatomy, 33, 141-146. https://doi.org/10.1007/s00276-010-0719-0

[16] Naitoh, M., Hiraiwa, Y., Aimiya, H., Gotoh, K. and Ariji, E. (2009) Accessory Mental Foramen Assessment Using Cone-Beam Computed Tomography. Oral Surgery, Oral Medicine, Oral Pathology, Oral Radiology, 107, 289-294. 
https://doi.org/10.1016/j.tripleo.2008.09.010

[17] Kalender, A., Orhan, K. and Aksoy, U. (2012) Evaluation of the Mental Foramen and Accessory Mental Foramen in Turkish Patients Using Cone-Beam Computed Tomography Images Reconstructed from a Volumetric Rendering Program. Clinical Anatomy, 25, 584-592. https://doi.org/10.1002/ca.21277

[18] Katakami, K., Mishima, A., Shiozaki, K., Shimoda, S., Hamada, Y. and Kobayashi, K. (2008) Characteristics of Accessory Mental Foramina Observed on Limited Cone-Beam Computed Tomography Images. Journal of Endodontics, 34, 14411445 .

Submit or recommend next manuscript to OALib Journal and we will provide best service for you:

- Publication frequency: Monthly

- 9 subject areas of science, technology and medicine

- Fair and rigorous peer-review system

- Fast publication process

- Article promotion in various social networking sites (LinkedIn, Facebook, Twitter, etc.)

- Maximum dissemination of your research work

Submit Your Paper Online: Click Here to Submit

Or Contact service@oalib.com 